\title{
A REPRESENTAÇÃO DO DOMÍNIO "GÊNERO" NO ÂMBITO DAS LINGUAGENS DOCUMENTÁRIAS: UM MAPEAMENTO CONCEITUAL EM INSTRUMENTOS TERMINOLÓGICOS
}

\section{LA REPRESENTACIÓN DEL DOMINIO “GÉNERO” EN EL ÁMBITO DE LOS LENGUAJES DOCUMENTARIOS: UN MAPEAMIENTO CONCEPTUAL EN INSTRUMENTOS TERMINOLÓGICOS}

\author{
Ana Rosa Pais Ribeiro* \\ Beatriz Decourt** \\ Tatiana de Almeida***
}

\begin{abstract}
RESUMO
Introdução: A pesquisa tem como foco principal os estudos do domínio "gênero" e é direcionada à análise de instrumentos de organização e representação da informação. Objetivos: Investiga conceitos e abordagens inerentes ao domínio em três Sistemas de Organização do Conhecimento (SOC) distintos e já consolidados em suas áreas de aplicação: o Tesauro para Estudos de Gênero e sobre Mulheres (TEG), os Descritores em Ciências da Saúde (DeCS) e a Classificação Decimal Universal (CDU). Metodologia: Utiliza o método de indução para a análise dos SOCs, que parte de conceitos pré-determinados para realizar a verificação, visando uma análise qualitativa e quantitativa dos Sistemas. Resultados: o estudo observou mudanças e

* Doutoranda em Ciência da Informação do Programa de Pós-Graduação em Ciência da Informação, convênio do Instituto Brasileiro de Informação em Ciência e Tecnologia e a Universidade Federal do Rio de Janeiro (IBICT/UFRJ). Mestre em Ciência da Informação. Tecnologista Sênior do Instituto Brasileiro de Geografia e Estatística-IBGE. E-mail: anarosa.ribeiro@globo.com

** Professora da Universidade Federal do Estado do Rio de Janeiro (UNIRIO), na Escola de Biblioteconomia. Mestre e Doutoranda em Ciência da Informação no convênio do Instituto Brasileiro de Informação em Ciência e Tecnologia e a Universidade Federal do Rio de Janeiro (IBICT/UFRJ). E-mail: beatrizdecourt@hotmail.com

*** Professora da Universidade Federal do Estado do Rio de Janeiro (UNIRIO), na Escola de Biblioteconomia. Doutoranda em Ciência da Informação no convênio do Instituto Brasileiro de Informação em Ciência e Tecnologia e a Universidade Federal do Rio de Janeiro (IBICT/UFRJ). E-mail: tatiana.almeida@unirio.br
\end{abstract}


Ana Rosa Pais Ribeiro, Beatriz Decourt, Tatiana de Almeida

A representação do domínio "gênero" no âmbito das linguagens documentárias: um mapeamento conceitual em instrumentos terminológicos

ressignificações em conceitos do domínio gênero, a partir da análise dos instrumentos. Conclusões: Conforme a literatura em Organização do Conhecimento tem historicamente demonstrado, o estudo atestou o modo como as condições sociopolíticas e culturais interferem nas representações documentárias.

Palavras-chave: Organização do Conhecimento. Gênero. Tesauro para Estudos de Gênero e sobre mulheres (TEG). Descritores em Ciência da Saúde (DeCS). Classificação Decimal Universal (CDU).

\section{INTRODUÇÃO}

O presente estudo trata da Organização do Conhecimento do domínio "gênero", com foco em instrumentos de organização e representação, que auxiliam na organização desse domínio, a partir do mapeamento de conceitos presentes no debate contemporâneo.

O uso de instrumentos de controle terminológico para apoio aos processos inerentes à Organização do Conhecimento, como a indexação e a classificação, por exemplo, torna-se imprescindível diante dos Sistemas de Recuperação da Informação. Isso se dá, principalmente, por conta do acesso online às bases de dados na internet e da organização de acervos visando o incremento na qualidade da informação recuperada pelos usuários.

O domínio "gênero" foi investigado em três Sistemas de Organização do Conhecimento distintos e já consolidados em suas áreas de aplicação: o Tesauro para estudos de gênero e sobre mulheres (TEG); os Descritores em Ciência da Saúde (DeCS); e a Classificação Decimal Universal (CDU).

Esses três instrumentos compreendem um objetivo comum que é organizar, facilitar e potencializar a recuperação dos documentos, além de representarem duas vertentes de trabalho diferenciadas no campo do tratamento documental.

O TEG e o DeCS são recursos utilizados no processo de indexação, que auxiliam na atribuição de assuntos aos documentos, o que também serve como um facilitador para o usuário, já que esses instrumentos têm como objetivo padronizar a linguagem utilizada tanto na organização realizada pelos 
Ana Rosa Pais Ribeiro, Beatriz Decourt, Tatiana de Almeida

A representação do domínio "gênero" no âmbito das linguagens documentárias: um mapeamento conceitual em instrumentos terminológicos

profissionais, quanto na recuperação realizada por esses usuários. Já a CDU é um esquema desenvolvido para representar documentos, a partir de áreas do conhecimento, para que possam ser alocados fisicamente, com o auxílio de uma notação formada por números, símbolos e letras.

Identificados os instrumentos, avaliou-se a adequação de cada um no contexto das questões de gênero a partir da observação da presença ou não dos termos característicos deste domínio e as possíveis relações existentes entre os mesmos.

O trabalho discute a Organização do Conhecimento e os estudos de "gênero", situando o escopo no qual se insere este domínio e explicitando suas bases teóricas. Em seguida, são apresentados os instrumentos terminológicos com as respectivas análises de conteúdo, a partir do conjunto de termos selecionados.

\section{ORGANIZAÇÃO DO CONHECIMENTO}

A Organização do Conhecimento (OC) como disciplina científica se ocupa da mediação entre um conhecimento socialmente produzido e sua posterior utilização, e é um dos principais focos de estudos da Ciência da Informação (GUIMARÃES, 2014).

A percepção da OC como ciência tem como marco a criação da International Society for Knowledge Organization (ISKO), fundada em 1989, que se tornou uma das mais importantes associações voltadas para temática da OC. Dalhberg (1993) esclarece que o termo organização do conhecimento já havia sido utilizado nos títulos das obras de Henry Evelyn Bliss, The Organization of Knowledge Organization and the system of the science; e, The Organization of Knowledge Organization in Libraries, publicados, respectivamente, em 1926 e 1936. Essa expressão foi utilizada, também, no título da tese de Dagobert Soergel, intitulada Organization of knowledge and documentation (1971), defendida na Alemanha, e na tese da própria Dalhberg,

Inf. Inf., Londrina, v. 22, n. 2, p. 208 - 234, maio/ago., 2017. 
Ana Rosa Pais Ribeiro, Beatriz Decourt, Tatiana de Almeida

A representação do domínio "gênero" no âmbito das linguagens documentárias: um mapeamento conceitual em instrumentos terminológicos

que foi publicada sob o título Foundation of Universal Organization of Knowledge.

Desde sua criação, a ISKO vem promovendo conferências internacionais a cada dois anos, em anos pares, sendo que a décima quarta conferência ocorreu no ano passado, no Rio de Janeiro. Também de dois em dois anos, em anos ímpares, ocorrem as conferências nacionais, levadas a cabo em cada um dos países signatários de um "Capítulo ISKO".

O Capítulo Brasil da ISKO (ISKO-Brasil) foi criado, efetivamente, em 2007 e teve a primeira conferência realizada em 2011. No âmbito dos eventos da ISKO-Brasil, observando as áreas temáticas para as quais são aceitos os trabalhos, a OC é estudada em três dimensões.

A primeira é a dimensão epistemológica onde se concentram os estudos sobre suas bases conceituais, históricas e metodológicas, além de seus diálogos interdisciplinares. De acordo com a ISKO-Brasil, essa é a dimensão na qual é discutida a natureza interdisciplinar da organização e representação do conhecimento bem como os impactos decorrentes do avanço das tecnologias da informação. Nesta dimensão também são discutidas suas bases históricas e metodológicas, além de seus desdobramentos conceituais. Nesse sentido, incluem-se abordagens às perspectivas investigativas e de divulgação do conhecimento do domínio em âmbito internacional.

A segunda é a dimensão aplicada na qual se encontram os estudos referentes aos modelos, instrumentos, produtos e estruturas de OC. As justificativas para esses estudos estão pautados nos objetivos primordiais da área que são: melhorar a recuperação, o acesso e a apropriação da informação. Desta forma, se torna necessário discutir padrões, modelos e formatos que levem à elaboração de instrumentos e metamodelos de produtos de OC, considerando especialmente os avanços tecnológicos. É nesta dimensão que o presente estudo se insere.

A terceira dimensão é a social, na qual são ressaltados os estudos relacionados à formação e atuação profissional em $\mathrm{OC}$, os conceitos de Ética, Cultura e Identidade, conjugados no domínio e também seu desenvolvimento

Inf. Inf., Londrina, v. 22, n. 2, p. 208 - 234, maio/ago., 2017. 
Ana Rosa Pais Ribeiro, Beatriz Decourt, Tatiana de Almeida

A representação do domínio "gênero" no âmbito das linguagens documentárias: um mapeamento conceitual em instrumentos terminológicos

sustentável. Nesse âmbito, é possível destacar o compromisso desse terceiro espaço da OC com a identidade e a diversidade cultural bem como com a inclusão social. Além disso, ressaltam-se também os aspectos que pressupõem uma especial ênfase na formação e a na atuação de profissionais na área, em especial no que tange à dimensão ética de seus fazeres.

O recorte da OC, na visão da ISKO, a partir de três grandes categorias de análise reforça o caráter múltiplo de estudos da área, como ressalta Gomes (2009), a seguir:

Percebe-se, então, que a OC é uma área de múltiplas aplicações. As pesquisas especificamente na área apontam para, no mínimo, dois aspectos importantes: de um lado, a abordagem teórica-filosófica voltada para questões epistemológicas ao analisar um domínio juntamente com as aplicações na organização de sistemas/tabelas de classificação e, de outro lado, os métodos empregados na elaboração propriamente dita dos sistemas, atividades que alguns autores consideram suplementar, mas que tem suas bases teóricas já sedimentadas (GOMES, 2009, p.63).

Os Sistemas de Organização do Conhecimento (SOCs) são a garantia de uma organização formal que vão interligar os elementos com vocabulários estruturados e formalizados, que servem para tratar e recuperar a informação, podendo ser utilizada tanto no ambiente da Web como no tradicional. Os SOCs são ferramentas importantes para a era da internet, pois existe também a necessidade de se fazer uma organização do acervo de documentos eletrônicos. O que diferencia um pouco é a forma de se organizar os documentos eletrônicos, que ocorre de forma contínua, já no acervo físico, são organizados de forma que cada documento possui o seu lugar no espaço. Os SOCs são representações do conhecimento, que por sua vez são modelos de abstração do mundo real, construídos para determinada finalidade.

Os objetivos dos sistemas podem mudar de acordo com a análise de cada autor, uns pensam em ferramentas que podem trazer uma interpretação com estruturas mais organizadas do conhecimento, outros acreditam que as

Inf. Inf., Londrina, v. 22, n. 2, p. 208 - 234, maio/ago., 2017. 
Ana Rosa Pais Ribeiro, Beatriz Decourt, Tatiana de Almeida

A representação do domínio "gênero" no âmbito das linguagens documentárias: um mapeamento conceitual em instrumentos terminológicos

bibliotecas digitais precisam ter uma ligação entre recursos digitais e objetos físicos (Hjorland, 2008; Hodge 2000).

Como afirmam Campos e Gomes (2003),

As formas de representação/organização dos diferentes domínios de conhecimentos vão implicar diretamente nos processos de transferência da informação, que hoje estão diretamente ligados à recuperação em meios eletrônicos (CAMPOS; GOMES, 2003, p.150).

Organizar um domínio requer, entre outros aspectos, a aquisição de conhecimentos sobre a história de formação do tema e sobre os conceitos inerentes ao mesmo. Nesse sentido, o conteúdo a seguir dá a conhecer um breve histórico dos estudos de gênero e apresenta os conceitos característicos do domínio que serão utilizados na análise dos instrumentos.

\section{ESTUDOS DE GÊNERO}

Segundo Meyer (2004), a história dos estudos de Gênero se entrelaça com a história dos movimentos de mulheres e seus "feminismos" e datam de fins do século XIX. É comum caracterizar esses estudos sob uma divisão de acontecimentos que a autora chama de ondas.

A primeira onda aglutina-se em torno do movimento sufragista, reivindicando o direito de votos para as mulheres. Já a segunda onda começa no contexto do pós segunda guerra na esteira da Declaração Universal dos Direitos Humanos (1948), com fortalecimento nas décadas de 1960 e 1970. Intensificam-se os debates desencadeados por movimentos de contestação intelectual e político nos Estados Unidos e na Europa. No Brasil se junta aos movimentos de oposição à ditadura militar.

Assim também, os estudos de "gênero" surgiram na academia como materialização ou reflexo de fatos que estavam ocorrendo na sociedade organizada com a ação de grupos diversos em prol do empoderamento das mulheres. A produção de conhecimento volta-se para essa realidade de luta

Inf. Inf., Londrina, v. 22, n. 2, p. 208 - 234, maio/ago., 2017. 
Ana Rosa Pais Ribeiro, Beatriz Decourt, Tatiana de Almeida

A representação do domínio "gênero" no âmbito das linguagens documentárias: um mapeamento conceitual em instrumentos terminológicos

para libertar a mulher da imagem de objeto da dominação patriarcal e passa a dar ênfase às desigualdades sociais entre homens e mulheres.

Entre as décadas 1980 e 1990, o "gênero" se consolida como categoria de análise e se configura uma resposta ou atualização do debate que passa a incorporar também a homossexualidade e a transexualidade como tema, com a adesão de lésbicas, gays e transexuais aos movimentos sociais.

As preocupações teóricas relativas ao gênero como categoria de análise só apareceram no final do século XX. Elas estão ausentes na maior parte das teorias sociais formuladas desde o século XVIII até o começo do século XX. De fato, algumas dessas teorias construíram a sua lógica sob analogias com a oposição masculino/feminino, outras reconheceram uma "questão feminina", outras ainda preocuparam-se com a formação da identidade sexual subjetiva, mas o gênero, como o meio de falar de sistemas de relações sociais ou entre os sexos, não tinha aparecido " (SCOTT, 1986, p.19).

O benefício da categoria de gênero é justamente permitir, e mais, exigir que o estudo e a análise sejam feitos sem definições preestabelecidas com relação aos significados ligados às diferenças sexuais. Essas definições devem, idealmente, ser buscadas em cada contexto.

De fato, Scott (1986) entende o gênero como uma categoria social que permite cotejar e diferenciar os papeis desempenhados por homens e mulheres e, dessa forma, a utilização da palavra gênero "coloca a ênfase sobre todo um sistema de relações que pode incluir o sexo, mas que não é diretamente determinado pelo sexo nem determina diretamente a sexualidade" (SCOTT, 1986, p. 7).

A partir daí, nas últimas décadas, a academia passou a incorporar temas e fontes de investigação vinculados ao cotidiano, à família, à sexualidade, às diferenças e ao trabalho dentre outros, que até então eram concebidos como menores e não autorizados pelo paradigma científico vigente. Isso porque as representações de gênero estão presentes - sendo construídas, reproduzidas e contestadas - em vários espaços, tais como as instituições, o mercado de 
Ana Rosa Pais Ribeiro, Beatriz Decourt, Tatiana de Almeida

A representação do domínio "gênero" no âmbito das linguagens documentárias: um mapeamento conceitual em instrumentos terminológicos

trabalho, os meios de comunicação, os movimentos sociais, as experiências coletivas e as escolhas individuais.

Para melhor compreensão do domínio em estudo, seguem duas definições para o conceito "gênero", tema central deste estudo:

Gênero é um conceito das ciências sociais que, grosso modo, se refere à construção social do sexo. Significa dizer que, no jargão da análise sociológica, a palavra sexo designa agora a caracterização anatomo-fisiológica dos seres humanos e, no máximo, a atividade sexual propriamente dita. O conceito de gênero ambiciona, portanto, distinguir entre 0 fato do dimorfismo sexual da espécie humana e a caracterização de masculino e feminino que acompanham nas culturas a presença de dois sexos na natureza. Este raciocínio apoia-se na ideia de que há machos e fêmeas na espécie humana, mas a qualidade de ser homem e ser mulher é condição realizada pela cultura (HEILBORN, 1994, p.1).

Essa autora aborda o conceito de "gênero" a partir do pensamento de que não são características sexuais ou biológicas que diferenciam os homens das mulheres, mas sim as diferenças expostas em sua personalidade e seu comportamento.

Já Jesus (2012, p.12) aponta a questão da diferenciação dos conceitos de "gênero" e orientação sexual a partir da seguinte afirmação:

Gênero se refere a formas de se identificar e ser identificada como homem ou como mulher. Orientação sexual se refere à atração afetivossexual por alguém de algum/ns gênero/s. Uma dimensão não depende da outra, não há uma norma de orientação sexual em função do gênero das pessoas, assim, nem todo homem e mulher é "naturalmente" heterossexual (JESUS, 2012, p.12).

$\mathrm{Na}$ revisão de literatura empreendida visando a identificação terminológica do domínio "gênero", o estudo de Jaqueline Gomes de Jesus Orientações sobre identidade de gênero: conceitos e termos. Guia técnico sobre pessoas transexuais, travestis e demais transgêneros, para formadores de opinião - foi referência importante por apresentar vários conceitos que estão presentes no debate contemporâneo trazendo a respectiva definição.

Inf. Inf., Londrina, v. 22, n. 2, p. 208 - 234, maio/ago., 2017. 
Ana Rosa Pais Ribeiro, Beatriz Decourt, Tatiana de Almeida

A representação do domínio "gênero" no âmbito das linguagens documentárias: um mapeamento conceitual em instrumentos terminológicos

O documento, com apenas 41 páginas que foi publicado em formato de e-book, em abril 2012, apresenta um conteúdo bem atual e tem uma proposta interessante no sentido de orientar o leitor no modo de utilização dos termos próprios do domínio de "gênero" visando a evitar a mescla de artigos e de pronomes, bem como de termos preconceituosos. Como disse a autora, a meta a ser alcançada com a publicação era divulgar informações cientificamente embasadas sobre identidade de gênero.

Nesse sentido, traz quase metade de suas páginas dedicadas ao Glossário de Termos "considerados inclusivos por representarem adequadamente o cotidiano de homens e mulheres transexuais, de travestis e outras pessoas transgênero". Inclui também "conceitos relacionados a gênero e orientação sexual" (JESUS, 2012, p. 24). São ao todo 33 termos que consubstanciam um vocabulário reconhecido pelas pessoas representadas, sendo essencial para valorizar a cidadania.

A análise dos instrumentos terminológicos aqui empreendida considerou uma lista de conceitos formada a partir da combinação de termos presentes também nos estudos de PINHO (2010) e NASCIMENTO; LEITE JUNIOR; PINHO (2015), na ambiência da Ciência da Informação, e no estudo de PINSKY (2016), na ambiência da História, o que resultou em vinte e cinco conceitos, assim relacionados em ordem alfabética: Cisgênero, Crossdressing, Diferença Sexual, Drag Queen, Drag King, Estudos de gênero, Feminismo, Gênero, Heterossexualidade, Homem, Homossexualidade, Identidade de gênero, Identidade sexual, Igualdade de gênero, Intersexo/Intersexualidade, Machismo, Mulher, Queer, Sexo, Sexualidade, Sexismo, Teoria queer, Transgêneros, Transexuais e Travestis. Esses termos configuram o que denominamos lista de termos selecionados.

$\mathrm{Na}$ próxima seção apresentam-se os três instrumentos identificados e também a análise da representação do domínio "gênero", a partir dos 25 termos selecionados.

Inf. Inf., Londrina, v. 22, n. 2, p. 208 - 234, maio/ago., 2017. 


\section{$4 \quad$ INSTRUMENTOS TERMINOLÓGICOS E O DOMÍNIO "GÊNERO"}

A análise dos instrumentos terminológicos deu-se tendo por base a lista de termos selecionados, citado anteriormente. Seguem, nas próximas subseções, a apresentação e o resultado da análise realizada em cada um dos instrumentos.

\section{1 "Gênero" na Classificação Decimal Universal (CDU)}

Os Sistemas de Classificação Bibliográfica foram criados para organizar o acervo de bibliotecas, facilitando o contato dos usuários com as informações que desejam, representando assim as classes de assuntos existentes no acervo. De acordo com Gomes (1996):

Classificar é ordenar, organizar, reunir segundo características comuns. Na Biblioteconomia esta organização é um imperativo e ela se dá através de instrumentos como tabelas de classificação - criadas com o fim específico de organizar fisicamente as coleções de documentos - e tesauros - criados para organizar os assuntos tratados nos documentos e/ou orientar os procedimentos de busca numa base de dados (GOMES, 1996, p.1).

Esse agrupamento de documentos semelhantes, distribuídos em classes e representados por símbolos (números, letras, sinais gráficos), é geralmente realizado com a utilização de um determinado Sistema de Classificação Bibliográfica ou Sistema de Organização do Conhecimento (SOC). Os Sistemas mais comumente utilizados no Brasil são: a Classificação Decimal Universal (CDU) e a Classificação Decimal de Dewey (CDD).

Os SOCs nascem com a proposta de abranger todo o conhecimento, dessa forma seria possível identificar os documentos com diferentes assuntos e pertencentes a todas as áreas do conhecimento. Para Dahlberg (2006):

a organização do conhecimento é a ciência que ordena a estruturação e sistematização dos conceitos, de acordo com suas características, que podem ser definidas como elementos de herança do objeto, e a aplicação dos conceitos e classes

Inf. Inf., Londrina, v. 22, n. 2, p. 208 - 234, maio/ago., 2017. 
dos conceitos ordenados pela indicação de valores, dos referentes conteúdos dos objetos ou assuntos. A partir dessa organização do conhecimento criam-se ferramentas que apresentam a interpretação organizada e estruturada do objeto, chamados de SOC. No contexto da ciência da informação, os SOCs ou esquemas de representação do conhecimento são instrumentos que fazem a tradução dos conteúdos dos documentos originais e completos, para um esquema estruturado sistematicamente, que representa esse conteúdo, com a finalidade principal de organizar a informação e o conhecimento e, consequentemente, facilitar a recuperação das informações contidas nos documentos (DAHLBERG, 2006, p.11).

A CDU é um sistema que representa o conhecimento em dez classes principais, divididas infinitamente. Usa sinais auxiliares para indicar vários aspectos especiais de um assunto ou relações entre assuntos. As classes possuem conjuntos de elementos com características em comum, que funcionam com no mínimo três dígitos, que são acompanhados por extensões e as subdivisões por símbolos. Possui notação mista, pois possui sinais, números decimais e letras. Notação é o código que vai representar os conceitos de uma classificação, vai facilitar o arranjo dos itens em um sistema de classificação, costuma-se dizer que é o endereço do livro na estante.

Constitui-se um sistema que possibilita a uniformização dos critérios de classificação dos documentos. É também um esquema facetado e de notação mista que se baseia no conceito de que o conhecimento pode ser dividido em classes principais, e estas podem ser subdivididas em subclasses, numa hierarquia decimal.

Com base nas classes principais existentes na CDU foi realizada a primeira etapa de busca pelos termos pertencentes ao vocabulário bibliográfico comum do domínio "gênero". Desta forma foi possível descrever como os mesmos são representados na estrutura deste esquema de classificação, o que pode ser visualizado nos quadros 1 e 2.

O quadro 1, a seguir, contempla a exploração dos 25 conceitos evidenciados por este estudo nas tabelas principais da CDU. 
Ana Rosa Pais Ribeiro, Beatriz Decourt, Tatiana de Almeida

A representação do domínio "gênero" no âmbito das linguagens documentárias: um mapeamento conceitual em instrumentos terminológicos

QUADRO 1: Representação do domínio "gênero" nas tabelas principais da CDU

\begin{tabular}{|c|c|}
\hline TERMOS & REPRESENTAÇÃO NA CDU \\
\hline Diferença sexual & $\begin{array}{l}\text { 612.6.057 Diferenciação sexual humana (61 Ciências médicas/ } \\
\text { 612 Fisiologia) }\end{array}$ \\
\hline Estudo de Gênero & $\begin{array}{l}\text { (3 Ciências Sociais) } \\
305 \text { - Estudo sobre o gênero. Inclusive o papel do sexo. Gênero. } \\
\text { Pessoas } \\
\text { do ponto de vista interdisciplinar } \\
\text { 305-055.1 Estudos sobre o homem } \\
\text { 305-055.2 Estudos sobre a mulher. A mulher e a sociedade } \\
\text { 305.5 Redesignação do gênero } \\
\text { (também está na Classe 616-089.844 Autoplastia. Cirurgia } \\
\text { plástica. Reconstrução) } \\
\text { Indica - 141.72 Feminismo (14 Sistemas e pontos de vista } \\
\text { filosóficos) }\end{array}$ \\
\hline Feminismo & 141.72 Feminismo (14 Sistemas e pontos de vista filosóficos) \\
\hline Gênero & $\begin{array}{l}\text { (34 Direito Civil) } \\
347.156 \text { - Gênero. Inclusive condição das mulheres }\end{array}$ \\
\hline Heterossexualidade & $\begin{array}{l}\text { não tem } \\
\text { Resultado mais aproximado: } \\
\text {-055.3 Pessoas segundo sua orientação sexual } \\
\text {-055.32 Heterossexuais }\end{array}$ \\
\hline Homossexualidade & 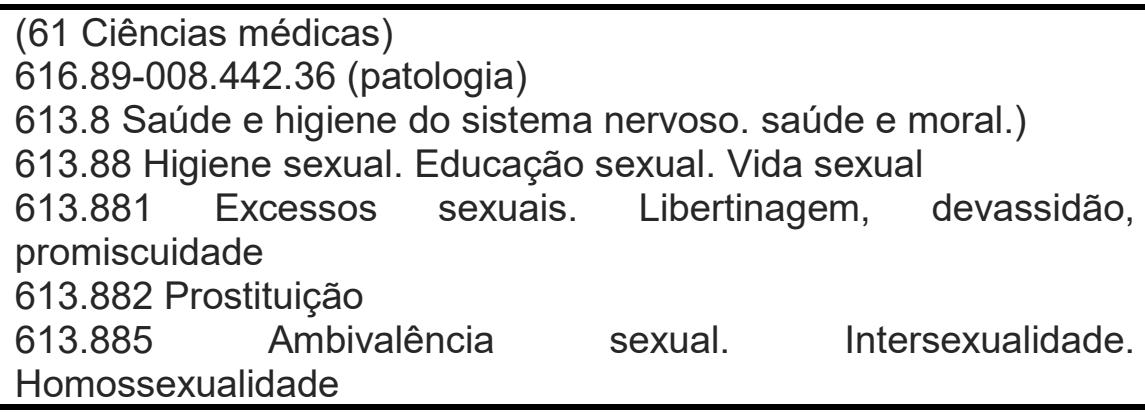 \\
\hline Intersexo & 613.885 Intersexualidade \\
\hline Sexo & $\begin{array}{l}\text { (31 Sociologia) } \\
\text { 316.83 Relações e práticas sexuais } \\
\text { 316.835 Relações heterossexuais } \\
\text { 316.837 Relações homossexuais, "gay" e lésbicas } \\
\begin{array}{l}\text { 57.017.4 Reprodução, Sexo e sexualidade (57 Ciências } \\
\text { biológicas) - palavra e não conceito! }\end{array}\end{array}$ \\
\hline Sexualidade & $\begin{array}{l}\text { (61 Ciências médicas / } 612 \text { Fisiologia) } \\
612.6 .057 \text { Sexualidade humana. Diferenciação sexual. Origem } \\
\text { dos sexos } \\
\text { 612.6.058 Hermafroditismo }\end{array}$ \\
\hline
\end{tabular}

Fonte: Elaboração das autoras a partir da análise do conteúdo da CDU.

Inf. Inf., Londrina, v. 22, n. 2, p. 208 - 234, maio/ago., 2017. 
Ana Rosa Pais Ribeiro, Beatriz Decourt, Tatiana de Almeida

A representação do domínio "gênero" no âmbito das linguagens documentárias: um mapeamento conceitual em instrumentos terminológicos

No âmbito das tabelas principais obtivemos apenas 1 resultado na busca pelo termo "gênero", que se apresentou em um desdobramento da grande classe "Ciências Sociais", na subclasse "Direito civil", sob o título de "Gênero. Inclusive condição das mulheres". Demonstrando, assim, a importância do tema relativo à condição das mulheres.

Já a busca pelo termo composto "estudo de gênero" mostrou-se retratado na CDU também na classe "Ciências Sociais", porém numa subclasse mais específica e detalhada, voltada para os estudos sobre o homem, sobre a mulher e também sobre redesignação de gênero.

Em relação ao assunto "sexo", este aparece vinculado à subclasse "Sociologia" e "Ciências Biológicas" sob aspectos tanto ligados às questões de sexualidade, quanto às questões de reprodução. Porém, o assunto "sexualidade" aparece somente na subclasse "Ciências médicas", mais especificamente no ramo da "Fisiologia".

Sobre os assuntos "machismo" e "feminismo" é notável salientar que o primeiro (machismo) não aparece em lugar algum da CDU, enquanto o segundo (feminismo) ocorre uma única vez vinculado à divisão "Sistemas e pontos de vista filosóficos".

Em relação à "diferença sexual" e "homossexualidade" ambos são representados somente na classe "Ciências médias" evidenciando uma abordagem mais voltada à patologização desses conceitos.

É importante observar que a exploração do instrumento demonstrou que a temática "gênero" na CDU aparece nas Classes constituídas pelas seguintes temáticas: 3 Ciências Sociais; 31 Sociologia; 34 Direito Civil; 39 Antropologia cultural. Etnologia. Etnografia. Usos e costumes. Tradições. Modo de vida. Folclore; 57 Ciências biológicas; 61 Ciências médicas; 612 Fisiologia; 616089.844 Autoplastia. Cirurgia plástica. Reconstrução; e na tabela auxiliar comum de pessoas e características pessoais.

É possível perceber, também, que essa temática aparece em grande parte vinculada às áreas Sociológicas, Médicas e do Direito. Demonstrando, por vezes, um olhar um tanto retrógrado e preconceituoso, como é o caso do

Inf. Inf., Londrina, v. 22, n. 2, p. 208 - 234, maio/ago., 2017. 
Ana Rosa Pais Ribeiro, Beatriz Decourt, Tatiana de Almeida

A representação do domínio "gênero" no âmbito das linguagens documentárias: um mapeamento conceitual em instrumentos terminológicos

assunto "Homossexualidade" que se apresenta numa notação coordenada em renque com outros assuntos como "excessos sexuais", "libertinagem", "devassidão", "promiscuidade" e "prostituição".

Cabe ressaltar que, no caso dos assuntos que não foram encontrados, foi realizada, também, uma busca por assunto equivalente ou similar aos procurados, pois foi considerada a questão da polissemia, ou seja, da multiplicidade de sentidos de uma palavra, no momento da análise do instrumento.

O quadro 2, contempla a exploração dos conceitos evidenciados por este estudo nas tabelas auxiliares da CDU.

QUADRO 2: Representação do domínio "gênero" nas tabelas auxiliares da CDU

\section{\begin{tabular}{l} 
TERMOS $\quad$ REPRESENTAÇÃO NA CDU \\
\hline
\end{tabular}}

\begin{tabular}{|c|c|}
\hline Homem & $\begin{array}{l}\text { (na tabela auxiliar comum de pessoas e características pessoais) } \\
\text { 055.1 Pessoas do sexo masculino. Homens } \\
\text { 055.15 Rapazes } \\
\text { 055.3 Pessoas segundo sua orientação sexual } \\
\text {-055.32 Heterossexuais } \\
\text {-055.34 Homossexuais. Gays. } \\
\text { Exemplo de combinações } \\
-055.34 / 34-055.1 \text { Gay masculino } \\
\text {-055.34/34-055.2 Lésbicas } \\
\text {-055.36 Bissexuais } \\
\text { Nota no conceito Homem: } \\
\text { Classificar outras características sexuais e quase sexuais com o } \\
\text { assunto p ex.: } \\
\text { 391.2 Travestismo (39 Antropologia cultural. Etnologia. Etnografia. } \\
\text { Usos e costumes. Tradições. Modo de vida. Folclore / } 391 \\
\text { Vestuário. Indumentária. } \\
\text { Traje nacional. Moda. Adornos) } \\
612.6-058 \text { Hermafroditismo (Intersexualidade) (61 Ciências médicas/ } \\
\text { 612 } \\
\text { Fisiologia) } \\
616.89-008.442 \text { Psicopatia sexual (61 Ciências médicas / } 616 \\
\text { Patologia. } \\
\text { Medicina Clínica) }\end{array}$ \\
\hline Mulher & $\begin{array}{l}\text { (na tabela auxiliar comum de pessoas e características pessoais) } \\
-055.2 \text { Pessoas do sexo feminino. Mulheres } \\
-055.25 \text { Moças }\end{array}$ \\
\hline
\end{tabular}

Fonte: Elaboração das autoras a partir da análise do conteúdo da CDU.

Inf. Inf., Londrina, v. 22, n. 2, p. 208 - 234, maio/ago., 2017. 
Ana Rosa Pais Ribeiro, Beatriz Decourt, Tatiana de Almeida

A representação do domínio "gênero" no âmbito das linguagens documentárias: um mapeamento conceitual em instrumentos terminológicos

No que corresponde às tabelas auxiliares da CDU, ou seja, as tabelas que apontam elementos complementares aos assuntos principais do esquema, podemos verificar que apenas os conceitos "homem" e "mulher" apareceram. É nítido também, a partir do Quadro 2, que a quantidade de exemplos e desdobramentos vinculados à temática "homem" é bem maior do que à temática "mulher", que aparece vinculada somente aos assuntos "pessoas do sexo feminino" e "moças".

Também cabe ressaltar que alguns conceitos não foram encontrados na CDU, como foi o caso de: Cisgênero; Transexuais; Travestis; Transgêneros; Crossdressing; Drag Queen; Drag king; Identidade Sexual; Identidade de gênero; Igualdade de gênero; Queer; Teoria Queer.

\section{2 "Gênero" nos Descritores em Ciência da Saúde (DeCS)}

A escolha dos Descritores de Ciências da Saúde (DeCS) baseou-se na informação existente na literatura sobre o domínio "gênero" que menciona a patologização, sobretudo no campo da psicologia e da psiquiatria.

O DeCS é a linguagem documentária utilizada pela Biblioteca Virtual de Saúde (BVS), pela base de dados da Literatura Latino-Americana e do Caribe de Informação em Ciências da Saúde (LILACS) e pela Biblioteca Regional de Medicina (BIREME). Trata-se de um vocabulário controlado na área médica e outras áreas relacionadas à saúde. Dentro desta perspectiva, a questão de "gênero" e os descritores que compõem este vocabulário apresentam estrita relação com patologias.

Desenvolvido a partir do Medical Subject Headings (MESH), o DeCS volta-se para uso na indexação de artigos de revistas científicas, livros, anais de congressos, relatórios técnicos, e outros tipos de materiais, assim como para a pesquisa e recuperação de assuntos da literatura científica nas bases de dados LILACS, entre outras.

Trata-se de um vocabulário controlado estruturado e disponibiliza os termos em três idiomas: inglês, espanhol e português. Seu sistema on-line 
Ana Rosa Pais Ribeiro, Beatriz Decourt, Tatiana de Almeida

A representação do domínio "gênero" no âmbito das linguagens documentárias: um mapeamento conceitual em instrumentos terminológicos

possibilita a consulta direta por palavras ou com a utilização dos índices alfabético, permutado ou hierárquico.

O índice alfabético apresenta os descritores ordenados alfabeticamente, o índice permutado apresenta os descritores que contêm a palavra expressa na busca, independentemente de seu posicionamento no descritor (mesmo no caso de descritores compostos); e, o índice hierárquico que apresenta os descritores organizados hierarquicamente, dos mais amplos aos mais específicos, utilizando a estrutura de árvore.

A estrutura hierárquica do DeCS baseia-se na divisão do conhecimento em classes e subclasses, o que possibilita a realização de pesquisa em termos mais abrangentes ou mais específicos ou até mesmo todos os termos que compõem determinada estrutura hierárquica. Segundo Pellizon (2016), a versão do DeCS para 2004 apresentava 159.958 descritores com sinônimos e definições nos três idiomas.

O DeCS apresentou como descritores autorizados, no domínio analisado, os termos Identidade de gênero, Sexismo, Sexo, Sexualidade, Transexualismo, Homossexualidade feminina, Homossexualidade masculina, Homens, Mulheres, Pessoas Transgêneros, Travestimo e ainda o termo Disforia de gênero, por ser um termo médico reconhecido na especialidade. Identificamos que alguns termos singulares também foram utilizados em descritores compostos como, por exemplo, Transtorno sexual e da identidade sexual. O mesmo ocorre com Gênero e saúde - ainda que gênero seja um termo considerado sinônimo de Identidade de Gênero. Além destes, outros descritores compostos usam a palavra gênero, sempre no singular.

A análise dos termos apresentou aspectos interessantes como foi o caso do termo Sexismo que traz a definição "Preconceito ou discriminação com base no gênero ou comportamento ou atitudes que nutrem papéis sociais estereotipados com base no gênero" o que inclui a ideia de machismo, mas este termo não aparece no campo Sinônimos em português. Ao mesmo tempo, apesar da definição de Feminismo apresentada pelo DeCS incluir parte da 
Ana Rosa Pais Ribeiro, Beatriz Decourt, Tatiana de Almeida

A representação do domínio "gênero" no âmbito das linguagens documentárias: um mapeamento conceitual em instrumentos terminológicos

ideia apresentada no termo Sexismo, esta não aparece no campo Relacionados.

Com a seleção dos termos encontrados no DeCS, a partir dos 25 conceitos considerados na lista de termos selecionados, procedeu-se ao levantamento da estrutura descritiva com o objetivo de verificar os elementos da hierarquização de cada termo bem como a existência de definições dos mesmos, permitindo melhor compreensão do domínio "gênero", e são apresentados no quadro 3 , a seguir.

QUADRO 3: Distribuição das categorias nos termos encontrados no DeCS

\begin{tabular}{|c|c|c|}
\hline TERMO & CATEGORIAS & $\begin{array}{l}\text { DENOMINAÇÃO } \\
\text { CATEGORIAS }\end{array}$ \\
\hline Identidade de gênero & $\begin{array}{l}\mathrm{F} \\
\mathrm{SP}\end{array}$ & $\begin{array}{l}\text { Psicologia e Psiquiatria } \\
\text { Saúde Pública }\end{array}$ \\
\hline Feminismo & $\begin{array}{l}\mathrm{K} \\
\mathrm{N}\end{array}$ & $\begin{array}{l}\text { Humanidades } \\
\text { Assistência à saúde }\end{array}$ \\
\hline Sexismo & $\mathrm{F}$ & Psicologia e Psiquiatria \\
\hline Sexo & $\mathrm{G}$ & Ciências Físicas \\
\hline Sexualidade & $\begin{array}{l}F \\
G\end{array}$ & $\begin{array}{l}\text { Psicologia e Psiquiatria } \\
\text { Ciências Físicas }\end{array}$ \\
\hline Transexualismo & $\mathrm{F}$ & Psicologia e Psiquiatria \\
\hline Pessoas transgênero & $\mathrm{M}$ & Pessoas \\
\hline $\begin{array}{l}\text { Homossexualidade } \\
\text { feminina }\end{array}$ & $\begin{array}{l}F \\
G\end{array}$ & $\begin{array}{l}\text { Psicologia e Psiquiatria } \\
\text { Ciências Físicas }\end{array}$ \\
\hline $\begin{array}{l}\text { Homossexualidade } \\
\text { masculina }\end{array}$ & $\begin{array}{l}\mathrm{F} \\
\mathrm{G}\end{array}$ & $\begin{array}{l}\text { Psicologia e Psiquiatria } \\
\text { Ciências Físicas }\end{array}$ \\
\hline Travestismo & $\mathrm{F}$ & Psicologia e Psiquiatria \\
\hline Homens & $\mathrm{M}$ & Pessoas \\
\hline Mulheres & $\begin{array}{l}\mathrm{F} \\
\mathrm{G}\end{array}$ & $\begin{array}{l}\text { Psicologia e Psiquiatria } \\
\text { Ciências Físicas }\end{array}$ \\
\hline
\end{tabular}

Fonte: Elaboração das autoras a partir da análise do conteúdo do DeCS

O quadro 3 apresenta os termos e suas Categorias, ou grandes classes, segundo a estrutura do DeCS. Dos doze termos encontrados a partir da listagem selecionada para pesquisa, oito são inseridos em Psicologia e Psiquiatria, o que reforça a ideia de patologização. Apenas os termos 
Ana Rosa Pais Ribeiro, Beatriz Decourt, Tatiana de Almeida

A representação do domínio "gênero" no âmbito das linguagens documentárias: um mapeamento conceitual em instrumentos terminológicos

Feminismo, Sexo, Pessoas Transgênero e Homens não contém esta categoria. $\mathrm{Na}$ classe Pessoas encontramos apenas os termos Homens e Pessoas transgênero. A temática em estudo apresenta relação, a partir da análise das categorias no DeCS com as Ciências Humanas, Assistência Social e Ciências da Saúde, Saúde Pública e Psicologia e Psiquiatria.

\section{3 "Gênero" no Tesauro para Estudos de Gênero e Sobre Mulheres - TEG ${ }^{1}$}

Esse tesauro foi desenvolvido por três cientistas sociais feministas e estudiosas do domínio "gênero": Cristina Bruschin², Danielle Ardaillon e Sanfra G. Unbehaum. Efetivamente publicado em 1998, é fruto de alguns caminhos percorridos pelas autoras em intentos anteriores dentro da perspectiva de organização de uma rede de pesquisadores dedicados ao tema, a Rede de Informações Bibliográficas na área de estudos de gênero e sobre mulheres.

Começou a ser idealizado ainda no início dos anos 1990, quando os estudos de Gênero começavam a ganhar espaço na academia. As pesquisadoras viviam $\mathrm{o}$ ambiente das discussões em torno do domínio "gênero" já havia bastante tempo e sempre se ressentiam da falta de um instrumento que refletisse a realidade dos estudos desenvolvidos no Brasil.

Desde sempre, havia a certeza de que o primeiro passo deveria ser a criação de uma linguagem ou vocabulário bibliográfico comum, que permitisse a indexação do acervo dos títulos elaborados no domínio de gênero.

Avaliaram e chegaram a usar o tesauro da UNESCO, mas logo perceberam que haveriam de enfrentar o grande desafio de construir um instrumento "sob medida", um tesauro específico para o domínio "gênero". Foi então que criaram o TEG no âmbito de um projeto de pesquisas de Gênero da Fundação Carlos Chagas, com foco na indexação do acervo de títulos da

1 Conteúdo elaborado a partir do texto que integra a publicação do TEG.

2 Considerada importante referência dos estudos de Gênero no Brasil

Inf. Inf., Londrina, v. 22, n. 2, p. 208 - 234, maio/ago., 2017. 
Ana Rosa Pais Ribeiro, Beatriz Decourt, Tatiana de Almeida

A representação do domínio "gênero" no âmbito das linguagens documentárias: um mapeamento conceitual em instrumentos terminológicos

Biblioteca Ana Maria Poppovic - BAMP, um dos primeiros centros de pesquisa a implantar um programa específico para esses estudos.

O TEG contempla o total de 1750 termos que são apresentados em ordem alfabética e também em ordem temática, que são características essenciais a qualquer tesauro: apresentação de termos e as relações entre eles. Justo nessa interrelação de conceitos e áreas temáticas reside sua potencialidade.

Este tesauro engloba nove áreas temáticas, a saber: Ciência e Tecnologia; Ciências Naturais e Saúde; Ciências Sociais e Cultura; Comunicação, Artes e Espetáculos ; Economia e Emprego; Educação; História e Mudança Social; Lei, Governo e Políticas Públicas; e, Linguagem, Literatura, Religião, Filosofia. E ainda três grupos de delimitadores, Etários, Temporais e Geográficos.

Na Lista Alfabética, os termos são apresentados em ordem alfabética acompanhado de sua estrutura conceitual, ou seja, para cada termo se apresenta a vinculação entre os conceitos. Esses relacionamentos podem ser de variados aspectos como analogia, oposição, descendência etc, e são disponibilizados em uma determinada hierarquia.

Essa hierarquia contempla as nove áreas temáticas que são representadas pela sigla em inglês "SG" (Subject Group); os grupos de delimitadores "DG" (delimiters groups) e nota explicativa do conceito SN (Scope Note), sendo que não necessariamente são apresentadas essas relações para todos os termos. Com efeito, foram utilizadas pelas autoras sempre que perceberam que era necessário para melhor compreensão do termo em questão.

A partir daí a organização do tesauro termo a termo traz a sua ascendência até o termo genérico "BT" (Broader Term), com a sua descendência de termos específicos "NT" (Narrower Term), assim como com as suas ligações com termos relacionados "RT" (Related Term), e indica também os termos cujo uso é recomendado "USE" (Used) ou aqueles que devem ser substituídos "UF" (Used for) (p.20).

Inf. Inf., Londrina, v. 22, n. 2, p. 208 - 234, maio/ago., 2017. 
Ana Rosa Pais Ribeiro, Beatriz Decourt, Tatiana de Almeida

A representação do domínio "gênero" no âmbito das linguagens documentárias: um mapeamento conceitual em instrumentos terminológicos

Já na Lista Temática, o TEG apresenta os termos separados por áreas temáticas, SG (Subject Groups), sendo que dentro de cada SG os termos estão organizados por ordem alfabética. Para cada termo são listados os delimitadores e são acompanhados apenas por seus termos relacionados (RT).

De acordo com a visão das autoras do TEG, essa Lista Temática "permite maior rapidez na procura de informação ou até mesmo na indexação, pois além de situar os termos dentro de áreas do saber ou de atividades bem delimitadas, ele indica os termos com os quais o termo principal mantém relações nem sempre são evidentes" (ARDAILLON; BRUSCHIN; UNBEHAUM. 1998. p. 21). As áreas temáticas são listadas, a seguir:

$$
\begin{aligned}
& \text { - Ciência e Tecnologia } \\
& \text { - Ciências Naturais e Saúde } \\
& \text { - Ciências Sociais e Cultura } \\
& \text { - Comunicação, Artes e Espetáculos } \\
& \text { - Economia e Emprego } \\
& \text { - Educação } \\
& \text { - História e Mudança Social } \\
& \text { - Lei, Governo e Políticas Públicas } \\
& \text { - Linguagem, Literatura, Religião e Filosofia }
\end{aligned}
$$

Como já mencionado, além dessas áreas temáticas, constam ainda três (3) grupos de delimitadores, "DG", que servem para aumentar o nível de precisão da indexação. Diz-se dos grupos etários, geográficos e históricos.

O exemplo abaixo visa proporcionar uma ideia dessa estrutura de distribuição dos termos por Lista Temática:

\section{CIÊNCIAS NATURAIS E SAÚDE}

Ciências biológicas, incluindo: Gravidez e parto biologia, química, fisiologia, Planejamento familiar e aborto zoologia e genética Saúde, incluindo: saúde mental, 
Ana Rosa Pais Ribeiro, Beatriz Decourt, Tatiana de Almeida A representação do domínio "gênero" no âmbito das linguagens documentárias: um mapeamento conceitual em instrumentos terminológicos

Ciências médicas, incluindo: saúde sexual, higiene e medicina, odontologia, nutrição

enfermagem e farmacologia Sexualidade

Esportes

\author{
abuso sexual \\ crimes contra crianças \\ crimes sexuais \\ direitos das crianças \\ incesto \\ misoginia \\ violência sexual \\ abrigos de mulheres \\ abuso sexual \\ comportamento sexual \\ crimes sexuais \\ incesto
}

Por fim, acrescenta-se que o tesauro aqui descrito representa a primeira versão levada a cabo pelas autoras que estavam cientes da necessária revisão temporal e também da ampliação e correção decorrentes do uso intensivo pela comunidade de pesquisadores e de bibliotecários no processamento de informações e do desenvolvimento de novos estudos no domínio "gênero". Certamente, podemos nos servir desse argumento para justificar o fato de que mesmo sendo um instrumento específico para o domínio "gênero", este tesauro não contemple todos os termos considerados de interesse neste estudo. Dos 25 termos, onze não foram encontrados.

\title{
5 CONSIDERAÇÕES FINAIS
}

A partir das análises realizadas neste estudo foi possível observar que o instrumento que abrangeu a maior parte dos termos selecionados foi o TEG.

Inf. Inf., Londrina, v. 22, n. 2, p. 208 - 234, maio/ago., 2017. 
Ana Rosa Pais Ribeiro, Beatriz Decourt, Tatiana de Almeida

A representação do domínio "gênero" no âmbito das linguagens documentárias: um mapeamento conceitual em instrumentos terminológicos

Com base nos instrumentos analisados foi também possível detectar mudanças e ressignificações em termos no domínio "gênero".

O vocabulário controlado DeCS caracterizou-se por abarcar termos menos atualizados que o TEG. Outra característica do DeCS é a representação da questão de gênero através de sua patologização, sobretudo no âmbito da psiquiatria. Tal fato pode ser compreendido na medida em que os aspectos enfocados no campo da medicina, de um modo geral, tratam de patologias. Entretanto, deve-se ressaltar que mesmo no âmbito das Ciências da Saúde existe uma tendência à mudança de comportamento a partir da possibilidade de realização de procedimentos e cirurgias voltados à adequação sexual.

Com o crescimento da produção científica do domínio "genêro" no campo da Medicina é provável que haja uma atualização no vocabulário com a inserção de novos termos específicos e relacionados. Este novo momento faz emergir diversas questões sociais e jurídicas que têm o potencial de proporcionar a compreensão do assunto por parte da sociedade.

Em relação ao Esquema de classificação CDU, percebeu-se que, apesar se sua estrutura permitir a abordagem de assuntos em áreas distintas, grande parte da temática "gênero" se concentra nas áreas de Sociologia, Ciências Médicas e Direito. Porém, isso não seria tão problemático se a aproximação nela contida não tivesse tão imbuída de preconceito e de uma visão pouco atualizada do assunto. De acordo com Novellino (1996):

A grande vantagem de um sistema de classificação é que, nele, as características de divisão que nortearam 0 classificacionista ficam visíveis. Os meta-conceitos são apresentados no corpo da tabela, demonstrando ao usuário a forma de organização daquela área do conhecimento. Além disso, num esquema de classificação, os conceitos que são subordinados a um conceito mais geral podem ser agrupados mais corretamente de acordo com a característica de divisão que guiou esta reunião. Características de divisão dão ao vocabulário transparência e assim enriquecem a busca, localizando e relacionando o conceito de acordo com suas características intrínsecas. (NOVELLINO, 1996, p.40).

Inf. Inf., Londrina, v. 22, n. 2, p. 208 - 234, maio/ago., 2017. 
Ana Rosa Pais Ribeiro, Beatriz Decourt, Tatiana de Almeida

A representação do domínio "gênero" no âmbito das linguagens documentárias: um mapeamento conceitual em instrumentos terminológicos

Essa vantagem dos esquemas de classificação também faz com que transpareça questões culturais e de contexto de criação dos mesmos. No caso da CDU serviu para demonstrar um olhar retrógrado e carregado de juízo préconcebido, no qual a representação do domínio "gênero" pode ser interpretada - e classificada - de forma discriminatória, como já foi dito anteriormente.

Novellino (1996) também chama a atenção para a compreensão de que "um sistema de classificação e um tesauro usados concomitantemente seriam complementares um ao outro. Lançando-se mão das vantagens que cada um apresenta", principalmente se ambos se mantiverem em constante atualização.

Por sua vez, o TEG que se configura uma linguagem documentária préconstruída, se mostrou ser um instrumento de organização de fácil utilização pelos seus usuários, bibliotecários e pesquisadores, além de muito importante para o domínio estudado, por ser focado diretamente nas questões de gênero. Porém, seria importante se apresentasse uma terminologia mais atualizada e específica, como o conteúdo terminológico que se conheceu nos trabalhos dos pesquisadores citados e que originou a lista de termos considerados neste estudo. Desta forma, poderia servir, tal qual o seu objetivo, como um instrumento de discussão teórico-metodológica nos estudos de gênero, dando visibilidade à área através da discussão de seus conceitos mais condizente com a realidade atual.

Porém, entendemos que os instrumentos terminológicos geralmente são elaborados a partir de um contexto histórico, social e cultural que interfere em sua representação. Desta forma, essas linguagens não se adequam de forma universal a todas as culturas. Por esses motivos torna-se importante ressaltar que as linguagens devem ser atualizadas constantemente, sobretudo em um domínio como o de "gênero" que está em ebulição e segue expandindo-se.

Destacamos ainda que seria interessante estender essa análise a outros tipos de SOC, como por exemplo, os sistemas facetados, com recorte por categorias, para que a transversalidade do tema gênero possa ser estudada de forma lógica também nesse tipo de Sistema.

Inf. Inf., Londrina, v. 22, n. 2, p. 208 - 234, maio/ago., 2017. 
Ana Rosa Pais Ribeiro, Beatriz Decourt, Tatiana de Almeida

A representação do domínio "gênero" no âmbito das linguagens documentárias: um mapeamento conceitual em instrumentos terminológicos

\section{REFERÊNCIAS}

ARDAILLON, D.; BRUSCHIN UNBEHAUM, C. S. G. Tesauro para estudos de gênero e sobre mulheres. São Paulo: Fundação Carlos Chagas. Ed.34, 1998. $304 \mathrm{p}$.

BIREME. Histórico. Disponível em:

$<$ http://www.paho.org/bireme/index.php?option=com content\&view=article\&id= $33 \% 3$ Ahistoria\&catid=38\%3Abireme-cerca\&ltemid=43\&lang=PT $>$. Acesso em 07 dez. 2016.

BIBLIOTECA VIRTUAL DE SAÚDE. Histórico. Disponível em: <http://brasil.bvs.br/vhl/sobre-a-bvs/historico-da-rede-bvs-no-brasil/>. Acesso em 07 dez. 2016.

CAMPOS, M. L. A.; GOMES, H. E. Princípios para modelagem de domínio: a posição de Barry Smith e de Ingetraut Dahlberg. Revista Ciência da Informação, Brasília, v. 41, n. 1, p. 81-94, jan./abr. 2014.

CAMPOS, M. L. A.; GOMES, H. E. Organização de domínios de conhecimento e os princípios ranganathanianos. Perspectivas em Ciência da Informação, Belo Horizonte, v. 8, n. 2, p. 150-163, jul./dez. 2003.

CASTRO, E. Terminologia, palavras-chave, descritores em saúde: qual a sua utilidade? São Paulo: Jornal brasileiro de AIDS, 2001, v.2, n.1, p.51-61.

Disponível em: < http://decs.bvs.br/P/Artigo.pdf>. Acesso em 07 dez. 2016.

DAHLBERG, I. Teoria do conceito. Ciência da Informação, Rio de Janeiro, v.7, n.2, p.101-107, 1978. RICI: Revista Ibero-americana. Ci. Inf., ISSN 1983-5213, Brasília, v. 4, n. 2, p. 53-73, ago./dez.2011. 73

DAHLBERG, I. Knowledge Organization: A New Science? Knowledge Organization, 33(1). 11-19, 2006.

GOMES, H. E. Classificação, tesauro e terminologia: fundamentos comuns. Palestra preparada para as Tertúlias do Departamento de Biblioteconomia da UNIRIO, apresentada em julho de 1996. Disponível em: $<$ http://www.conexaorio.com/bit//tertulia/tertulia.htm>. Acesso em 03 de out. 2016.

GOMES, H. E. Tendências da pesquisa em organização do conhecimento. Tendências da Pesquisa Brasileira em Ciência da Informação, v.2, n.1, p.60-88, 2009. Disponível em: < http://basessibi.c3sl.ufpr.br/brapci/index.php/article/view/0000007771/a9da848c 0f429ecab5cdf67f1f16b07b>. Acesso em:03 Out 2016 
GUIMARÃES, J. A. C. Análise de domínio como perspectiva metodológica em organização da informação. Revista Ciência da Informação, Brasília, DF, v. 41 n. 1, p.13-21, jan./abr., 2014.

HEILBORN, M. L. "De que gênero estamos falando? In: Sexualidade, Gênero e Sociedade. Ano 1, n 2 CEPESC/IMS/UERJ, 1994.

JESUS, Jaqueline G. (2010). Pessoas transexuais como reconstrutoras de suas identidades: reflexões sobre o desafio do direito ao gênero. In: Galinkin, Ana L. \& Santos, Karine B. (orgs.), Anais do Simpósio Gênero e Psicologia Social: diálogos interdisciplinares, 80-89. Disponível em: $<$ https://www.researchgate.net/publication/233869298 Pessoas transexuais c omo reconstrutoras de suas identidades reflexoes sobre o desafio do dire ito ao genero>. Acesso em 25 mar 2017.

JESUS, Jaqueline Gomes de. Orientações sobre identidade de gênero: conceitos e termos. Brasília. 42 p., 2012. Disponível em:

$<$ http://www.diversidadesexual.com.br/wpcontent/uploads/2013/04/G\%C3\%8A NERO-CONCEITOS-E-TERMOS.pdf> Acesso em 07 dez. 2016.

MEYER, Dagmar Estermann. Teorias e Políticas de Gênero: fragmentos históricos e desafios atuais. Revista Brasileira de Enfermagem, Brasília (DF), v.57, n.1, p.8-13, jan/fev, 2004.

NASCIMENTO, F. A.; LEITE JUNIOR, F. F.; PINHO, F. B. A. Tipologias e classificações: um estudo sobre as temáticas de gênero e sexualidade no manual diagnóstico e estatístico de transtornos mentais (dsm). Encontro Nacional de Pesquisa em Ciência da Informação, v. 16, s/n, 2015.

NOVELLINO, Maria Salet Ferreira. Instrumentos e metodologias de representação da informação. Informação \& informação. Londrina, v.1, n.2, p.37-45, jul./dez. 1996.

PELLIZZON, Rosely de Fátima. Pesquisa na área da saúde: 1. Base de dados DeCS (Descritores em Ciências da Saúde). Acta Cir. Bras., São Paulo, v. 19, n. 2, p. 153-163, Abr. 2004. Disponível em:

$<$ http://www.scielo.br/scielo.php?script=sci arttext\&pid=S010286502004000200 013\&lng=en\&nrm=iso>. Acesso em 07 dez. 2016.

PINHO, Fabio Assis. Aspectos éticos em representação do conhecimento em temáticas relativas à homossexualidade masculina: uma análise da precisão em linguagens de indexação brasileiras. Tese de doutorado. Marília, 2010, $149 \mathrm{f}$. 
Ana Rosa Pais Ribeiro, Beatriz Decourt, Tatiana de Almeida

A representação do domínio "gênero" no âmbito das linguagens documentárias: um mapeamento conceitual em instrumentos terminológicos

PINSKY, Carla Bassanezi. Estudos de Gênero e História Social. Revista

Estudos Feministas, Florianópolis, v. 17, n. 1, p. 159-189, Jan. 2009. ISSN

0104-026X. Disponível em:

$<$ https://periodicos.ufsc.br/index.php/ref/article/view/S0104026X200900010000

9>. Acesso em 07 dez. 2016.

POLITIZE... Conteúdo do site: <http://www.politize.com.br/movimentofeminista-historia-no-brasil/>. Acesso em 07 dez. 2016.

SCOTT, J. W. "Gender: A Useful Category of Historical Analysis". The

American Historical Review, vol. 91, nº 5. (Dec,1986), pp. 1053-1075.

SOERGEL, Dagobert. Organization of knowledge and documentation. 1971.

Disponível em: <http://www.dsoergel.com/>. Acesso em 03 jul. 2016

SOUZA, Rosali Fernandez de. Organização do conhecimento. In.: TOUTAIN, Lídia M. B. B. (org.). Para entender a Ciência da Informação. Salvador:

EDUFBA, 2007. p. 103-124.

\title{
Title
}

The representation of the "gender" domain in the field of documentary languages: a conceptual mapping in terminological instruments

\begin{abstract}
Introduction: The research has as main focus the studies of the domain "gender" and is directed to the analysis of instruments of organization and representation of the information. Objectives: Investigate concepts and approaches inherent to the domain in three distinct Knowledge Organization Systems (SOCs) and already consolidated in its areas of application: the Thesaurus for Gender and Women Studies (TEG), the Descriptors in Health Sciences (DeCS) and the Universal Decimal Classification (CDU). Methodology: It uses the induction method to analyze the SOCs, which starts from pre-determined concepts to perform the verification, aiming at a qualitative and quantitative analysis of the Systems. Results: the study observed changes and resignifications in concepts of the gender domain, from the analysis of the instruments. Conclusions: As the literature on the Organization of Knowledge has historically demonstrated, the study attested how socio-political and cultural conditions interfere with documentary representations.
\end{abstract}

Keywords: Organization of Knowledge. Gender. Thesaurus for Gender Studies and Women (TEG). Descriptors in Health Science (DeCS). Universal Decimal Classification (CDU).

Inf. Inf., Londrina, v. 22, n. 2, p. 208 - 234, maio/ago., 2017. 
Ana Rosa Pais Ribeiro, Beatriz Decourt, Tatiana de Almeida

A representação do domínio "gênero" no âmbito das linguagens documentárias: um mapeamento conceitual em instrumentos terminológicos

\section{Título}

La representación del dominio "género" en el ámbito de los lenguajes documentarios: un mapeamiento conceptual en instrumentos terminológicos

\section{Resumen}

Introducción: La investigación tiene como foco principal los estudios del dominio "género" y se dirige al análisis de instrumentos de organización y representación de la información. Objetivos: Investiga conceptos y enfoques inherentes al dominio en tres Sistemas de Organización del Conocimiento (SOC) distintos y ya consolidados en sus áreas de aplicación: el Tesauro para Estudios de Género y sobre Mujeres (TEG), los Descriptores en Ciencias de la Salud (DeCS) y la Clasificación Decimal Universal (CDU). Metodología: Utiliza el método de inducción para el análisis de los SOCs, que parte de conceptos predeterminados para realizar la verificación, buscando un análisis cualitativo y cuantitativo de los Sistemas. Resultados: el estudio observó cambios y resignificaciones en conceptos del dominio género, a partir del análisis de los instrumentos. Conclusiones: De acuerdo con lo que la literatura en Organización del Conocimiento ha históricamente demostrado, el estudio atestó el modo en que las condiciones sociopolíticas y culturales interfieren en las representaciones documentales.

Palabras clave: Organización del Conocimiento. Género. Tesauro para Estudios de Género y sobre Mujeres (TEG). Descriptores en Ciencias de la Salud (DeCS). Clasificación Decimal Universal (CDU).

Recebido: 10.03 .2017

Aceito: 25.08.2017 